Archived version from NCDOCKS Institutional Repository http://libres.uncg.edu/ir/asu/

\title{
Appalachľan
}

B O O N E, N O R T H C A R O L I N A

\section{Male Care Of Infants In A Siamang (Symphalangus syndactylus) Population Including Socially Monogamous And Polyandrous Groups}

\author{
By: Susan Lappan
}

\begin{abstract}
While male parental care is uncommon in mammals, siamang (Symphalangus syndactylus) males provide care for infants in the form of infant carrying. I collected behavioral data from a cohort of five wild siamang infants from early infancy until age 15-24 months to identify factors affecting male care and to assess the consequences of male care for males, females, and infants in a population including socially monogamous groups and polyandrous groups. There was substantial variation in male caring behavior. All males in polyandrous groups provided care for infants, but males in socially monogamous groups provided substantially more care than males in polyandrous groups, even when the combined effort of all males in a group was considered. These results suggest that polyandry in siamangs is unlikely to be promoted by the need for "helpers." Infants receiving more care from males did not receive more care overall because females compensated for increases in male care by reducing their own caring effort. There was no significant relationship between indicators of male-female social bond strength and male time spent carrying infants, and the onset of male care was not associated with a change in copulation rates. Females providing more care for infants had significantly longer interbirth intervals. Male care may reduce the energetic costs of reproduction for females, permitting higher female reproductive rates.
\end{abstract}

Lappan, S. Male care of infants in a siamang (Symphalangus syndactylus) population including socially monogamous and polyandrous groups. Behav Ecol Sociobiol 62, 1307-1317 (2008). https://doi.org/10.1007/ s00265-008-0559-7. Publisher version of record available at: https://link.springer.com/article/10.1007/ s00265-008-0559-7 


\title{
Male care of infants in a siamang (Symphalangus syndactylus) population including socially monogamous and polyandrous groups
}

\author{
Susan Lappan
}

Received: 1 May 2007 /Revised: 25 January 2008 / Accepted: 1 February 2008 / Published online: 27 February 2008

(C) Springer-Verlag 2008

\begin{abstract}
While male parental care is uncommon in mammals, siamang (Symphalangus syndactylus) males provide care for infants in the form of infant carrying. I collected behavioral data from a cohort of five wild siamang infants from early infancy until age 15-24 months to identify factors affecting male care and to assess the consequences of male care for males, females, and infants in a population including socially monogamous groups and polyandrous groups. There was substantial variation in male caring behavior. All males in polyandrous groups provided care for infants, but males in socially monogamous groups provided substantially more care than males in polyandrous groups, even when the combined effort of all males in a group was considered. These results suggest that polyandry in siamangs is unlikely to be promoted by the need for "helpers." Infants receiving more care from males did not receive more care overall because females compensated for increases in male care by reducing their own caring effort. There was no significant relationship between indicators of male-female social bond strength and male time spent carrying infants, and the onset of male care was not associated with a change in copulation rates. Females providing more care for infants had significantly longer interbirth intervals. Male care may reduce the energetic costs of reproduction for females, permitting higher female reproductive rates.
\end{abstract}

Communicated by S. Alberts

S. Lappan $(\bowtie)$

Division of EcoScience, Ewha University,

Seoul 120-750, Republic of Korea

e-mail: lappan@nyu.edu
Keywords Parental care $\cdot$ Siamang $\cdot$ Symphalangus syndactylus $\cdot$ Social monogamy $\cdot$ Facultative polyandry

\section{Introduction}

Biparental care in mammals is most common among carnivores, primates, and rodents, and is often associated with social monogamy or cooperative breeding (CluttonBrock 1991; Jennions and MacDonald 1994; Kleiman and Malcolm 1981), although male parental care has also been reported in species with other grouping and mating patterns (Borries et al. 1999; Buchan et al. 2003). In many species displaying biparental care, there is intraspecific variation in the quantity of care provided by males (Webb et al. 1999). Variation in the quantity or quality of male care in biparental mammals has been shown to affect infant survivorship (Gubernick and Teferi 2000; McInroy et al. 2000; Wright 2006), interbirth intervals (IBI; Cantoni and Brown 1997), and offspring development (Bester-Meredith and Marler 2003; Frazier et al. 2006; McInroy et al. 2000). Therefore, in biparental species, male behavior may be an important determinant of offspring survival and development.

Social monogamy with biparental care may evolve where certainty of paternity is relatively high or the ability of males to obtain multiple mates is low (Kleiman and Malcolm 1981). Male opportunities to seek additional mates may be limited by female spatial dispersion, leading to social monogamy (Komers and Brotherton 1997). However, female spatial dispersion need not always lead to pair-bonding and social monogamy (Dunbar 1995; Mitani 1990b; van Schaik and Dunbar 1990). Similarly, social monogamy, with its (presumably) concomitant relatively high certainty of paternity, does not guarantee extensive male parental investment in mammals (Komers 
and Brotherton 1997; van Schaik and Paul 1997; Whitten 1987). Therefore, other factors must also affect a male's decision whether to provide parental care.

Male parental care is usually associated with social monogamy or cooperative breeding in small-bodied anthropoid primates (Wright 1990). However, direct male care of infants has never been reported for most gibbon species (Hylobatidae), despite the prevalence of social monogamy in this family. Siamangs (Symphalangus syndactylus) are apparently unique among the hylobatids in that they exhibit biparental care of infants in the wild (Chivers 1974; Chivers and Raemaekers 1980; Gittins and Raemaekers 1980) and in captivity (Alberts 1987; Dielentheis et al. 1991). Chivers (1974), Chivers and Raemaekers (1980), and Gittins and Raemaekers (1980) describe wild siamangs as displaying exclusive female care during the early stages of infant development, followed by the gradual transfer of most infant care responsibilities from the female to the male in the second year of infant life. However, Palombit (1992) did not report male involvement in infant care in the single siamang group that contained an infant of appropriate age during his study. This suggests that the pattern of infant care may vary between groups, and that biparental care is not obligate for siamangs. While siamangs are generally described as being socially monogamous (Chivers 1974; Chivers and Raemaekers 1980; Palombit 1994, 1996), the siamang population in the Way Canguk Research Area in southern Sumatra includes both socially monogamous and polyandrous groups (Lappan 2007a, b, O'Brien and Kinnaird, unpublished data). Therefore, male siamangs apparently make facultative decisions about both grouping and mating patterns and investment in infant care.

I present the results of a 2-year study of parenting behavior in three polyandrous and two socially monogamous groups of wild siamangs in the Bukit Barisan Selatan National Park, Sumatra, Indonesia, and describe the general pattern of infant care in the study groups and the range of variation in male caring behavior. In polyandrous groups, rates of aggression between males are low, and multiple males copulate with the female and provide care for her offspring (Lappan 2007b). Therefore, I also explicitly consider the relationship between grouping and mating patterns and male caring behavior. I examine the relationship between male and female care, and between female care and IBI, and discuss possible causes of variation in male behavior and the potential effect of male care on the fitness of males, females, and infants. In several other facultatively polyandrous species, the presence of additional helpers is strongly associated with increased offspring survivorship (Davies 1986; Davies and Hatchwell 1992; Garber et al. 1984), reduced costs of care to males (Achenbach and Snowdon 2002; Bales et al. 2000; Price 1992), or reduced maternal expenditure (Bales et al. 2002;
Cleveland and Snowdon 1984; Fite et al. 2005), suggesting that adults in polyandrous groups may benefit from care by secondary males. If male care is an important factor promoting polyandrous grouping in siamangs, then at least one of the following predictions should be upheld: (1) polyandry should be associated with (a) an increase in the total quantity of parental care that infants receive or (b) the same quantity of nonmaternal care at a reduced cost for each caring male, relative to social monogamy; and (2) polyandry should be associated with reduced energetic investment in each reproductive attempt by the female, facilitating more rapid offspring production.

\section{Materials and methods}

Study area and siamang population

The Way Canguk Research Area is located in the southern part of the Bukit Barisan Selatan National Park on Sumatra, Indonesia. The research area, run by the Wildlife Conservation Society-Indonesia Program (WCS-IP) and the Indonesian Ministry of Forestry's Department for the Protection and Conservation of Nature (PHKA), includes 900 ha of forest contiguous with large areas of disturbed and undisturbed lowland rain forest. The study area consists of a mosaic of primary forest and forest damaged by drought, wind throws, earthquakes, and fire, (Kinnaird and O'Brien 1998; O'Brien et al. 2003) and is covered by a grid of trails at $200 \mathrm{~m}$ intervals. Annual precipitation ranges from 1,600 to $4,000 \mathrm{~mm}$, and is weakly seasonal (Kinnaird and O'Brien 2005).

The Way Canguk research area contains all or part of the home ranges of 36-37 groups of siamangs (O'Brien et al. 2003). "Floaters," or adults not associated with social groups, are very rare at Way Canguk (O'Brien and Kinnaird, unpublished data). Several habituated groups of wild siamangs at this site have been the subjects of behavioral studies by WCS-IP staff and students since 1998 , and an annual census of the entire population of 36 37 groups was conducted from 1998 to 2002 (O'Brien et al. 2003). These census data reveal that the adult sex ratio of the study population is male biased, and siamang groups containing two or more adult males are relatively common in this population, although pairs with immatures represent the most common grouping pattern (O'Brien and Kinnaird, unpublished data). I have suggested elsewhere that the male-biased adult sex ratio may result from greater female than male dispersal-related mortality in this population (Lappan 2007a).

The study area was damaged as a result of wildfires associated with the El Niño-Southern Oscillation (ENSO) event of 1997. As detailed demographic data were not 
collected from Way Canguk siamangs before these fires, it is not clear to what extent the demographic characteristics of the population were affected by the fires. However, there are no siamang home ranges consisting entirely of firedamaged habitat, suggesting that the area available for siamangs was reduced by the fires (O'Brien et al. 2003). Therefore, the possibility that the fires resulted in compression of the siamang population or distortion of normal patterns of dispersal and group formation, resulting in a male-biased sex ratio and multimale grouping in this population, cannot be excluded. However, multimale grouping has been reported in a number of gibbon studies (Fuentes 2000), and group composition and census data from other gibbon species reveal male-biased adult sex ratios in wild populations of Hylobates lar (Carpenter 1940; Sommer and Reichard 2000), Hylobates agilis (Mitani 1990a), and Hoolock hoolock (Ahsan 2000), and in Way Canguk siamangs (O'Brien and Kinnaird, unpublished data).

Siamang births have been recorded throughout the annual cycle, and there is no evidence of breeding seasonality. Siamang gestation periods are estimated to be between 6.2 and 7.9 months (Geissmann 1991), and the mean IBI for Way Canguk siamangs was estimated to be 2.6 years (for groups with home ranges not affected by the ENSO wildfires) or 2.8 years (for groups with home ranges adjacent to or including fire-damaged habitat) on the basis of cross-sectional data collected in annual censuses of the 36-37 groups in the study area between 1998 and 2001 (O'Brien et al. 2003). All females in this study were observed copulating within 12 months after parturition, and visible cyclical changes in the color and shape of female genitalia suggest that some females may cycle for a year or more before conception (Lappan 2005).

Five groups of siamangs were chosen for the study based on proximity to the research camp and the birth of a young infant in the group within a few months of the onset of the study. Compositions of the study groups throughout the study period are shown in Fig. 1. I have described the methods by which individual age classes were assigned elsewhere (Lappan 2007b). Demographic (group size, mean IBI) and ecological (home range size, number of reproductive-size strangling figs) characteristics of the study groups were within typical ranges for siamang groups at Way Canguk living in healthy forests (O'Brien et al. 2003). Four of the five groups were fully habituated to human observers when they were selected for observations, whereas the fifth (group A) required 1 month of additional follows before habituation was complete. Only data collected after full habituation were included in this study. All individuals were individually recognizable based on facial and body features.

\section{Behavioral data collection}

Three field assistants and I collected behavioral data during sleeping-tree-to-sleeping-tree follows. Groups were followed on a rotating basis, and each group was generally followed for 4 to 6 days each month, except during a 6-week period in September-October 2001 and a 5-week period from December 2001 to Jan 2002 when no research activities were conducted. We collected behavioral data

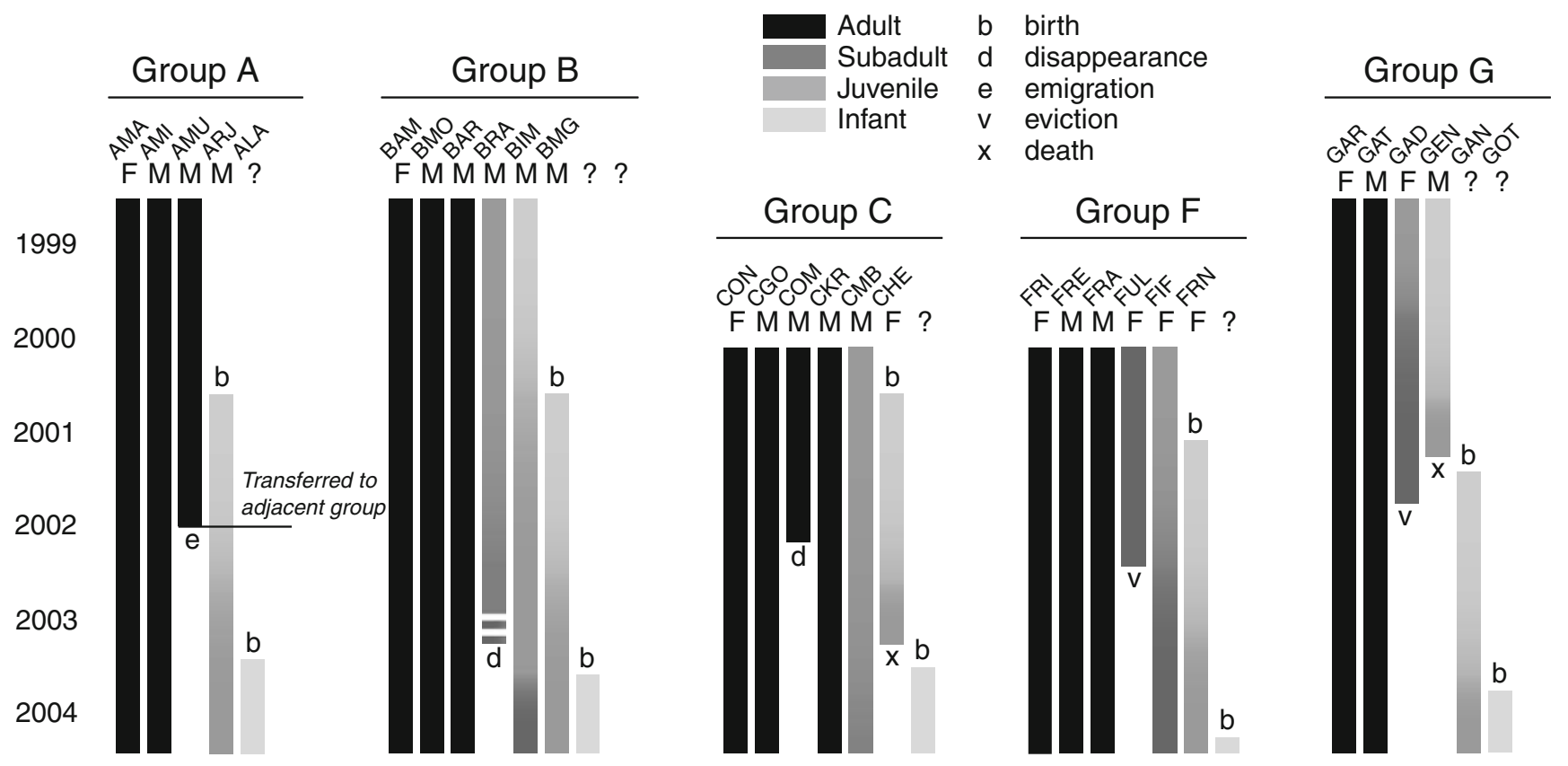

Fig. 1 Composition of the study groups from June 2000 to June 2004. $M$ male, $F$ female, ? sex unknown 
from group B from October 2000, from groups A and C from November 2000, from group F from February 2001, and from group G from May 2001. Behavioral data were collected from all groups until August 2002, and group compositions were monitored through December 2004. I included data collected by field assistants only after $\geq 3$ months of training and verification of interobserver reliability.

Instantaneous samples of infant activity were recorded at 5-min intervals. I chose a single adult as a focal individual on each day, and the observers recorded instantaneous samples of adult activity, distance from each other adult, and distance from the infant at 5-min intervals. When the infant or the focal adult interacted socially with another individual or individuals, the identities of all involved individuals were recorded. Caring behaviors directed toward infants included suckling, carrying, grooming, and social play. As only females can nurse infants and suckling could not be reliably detected during many behavioral samples, I did not include suckling behavior in the analyses of the quantity of parental care that infants received. Therefore, infant care was defined as an interaction involving an infant and another individual when the other individual carried the infant, groomed the infant, or played with the infant. The vast majority ( $>98 \%)$ of observations of infant care in this study involved infant carrying.

\section{Statistical analysis}

Analyses were conducted using daily means of hourly mean proportions of time spent engaging in a behavior, unless otherwise indicated. The variable employed for the statistical analyses of infant care was the mean proportion of the infant's time during which it received care from adults of the class of interest (e.g., males, females, all group members). All proportional data were transformed before analysis by parametric statistical tests using the transformation:

$p^{\prime}=\operatorname{arcsine}($ square $\operatorname{root}((x+3 / 8) /(n+3 / 4)))$

where $x$ is the number of observations of a behavior and $n$ is the number of cases where the presence or absence of that behavior was noted. This transformation approximates the normal distribution and is preferable to the arcsine-square root transformation where many values are near 0 or 1 (Zar 1996).

\section{Results}

Social monogamy and polyandry coexist in the study population

While siamangs are usually described as being socially monogamous, study groups A, B, C, and F contained two adult males for most or all of the study period (Fig. 1). In multimale groups $\mathrm{A}, \mathrm{B}$, and $\mathrm{C}$, both males were observed copulating with the female, and mtDNA data from a concurrent study indicate that neither male could have been her offspring or maternal sibling (Lappan 2007a). Therefore, these groups were described as socially and sexually polyandrous. In group $\mathrm{F}$, however, copulation between one male (FRA) and the female was never observed, and this male and female had matching mtDNA haplotypes (Lappan 2007a). While this is not conclusive evidence of a close genetic relationship, siamangs in this area displayed a high haplotype diversity, making the occurrence of identical haplotypes in members of a social group in the absence of a close genetic relationship improbable (Lappan 2007a). Therefore, the most parsimonious interpretation is that this group was a socially monogamous group with a retained adult offspring of the female (and possibly the male). In group $\mathrm{G}$, only a single male lived and copulated with the adult female (Fig. 1). In groups $\mathrm{A}, \mathrm{B}$, and $\mathrm{C}$, both males were observed carrying infants, whereas in groups $F$ and $G$, only a single male was observed carrying the infant. In group $\mathrm{F}$, the only male that was observed copulating with the female was also the only male that carried her offspring. Throughout this study, and other studies of the same population (Nurcahyo, unpublished data; Kinnaird and O'Brien, unpublished data), copulations between members of different social groups have not been recorded. As the study included several groups with habituated neighbors, and floaters are very rare, this is unlikely to be a result of the presence of observers, but rather suggests that most copulations involve members of the same social group.

Males and females showed variability in infant care

Infants were carried by their mothers nearly all of the time during the first 2 months of life, and all infants except BMG were in physical contact with their mothers all of the time before 3 months of age. After infant age 3 months, the mean proportion of time that infants spent being carried by their mothers declined consistently, and there was substantial variation in the proportion of time that females spent carrying infants (Fig. 2). Females carried infants over 16 months of age less than 0.2 of the time.

Adult males in all five groups were observed carrying infants, which suggests that male involvement in infant care is common in this population. However, the proportion of time that males spent carrying infants varied dramatically between individuals and group types (Fig. 2). Adults were also observed playing with and grooming infants. However, adult males and females spent an average of only 0.002 of their time engaging in social play with infants, and social grooming with adult females and males occupied only 0.003 and 0.001 of the infant's time, respectively. 

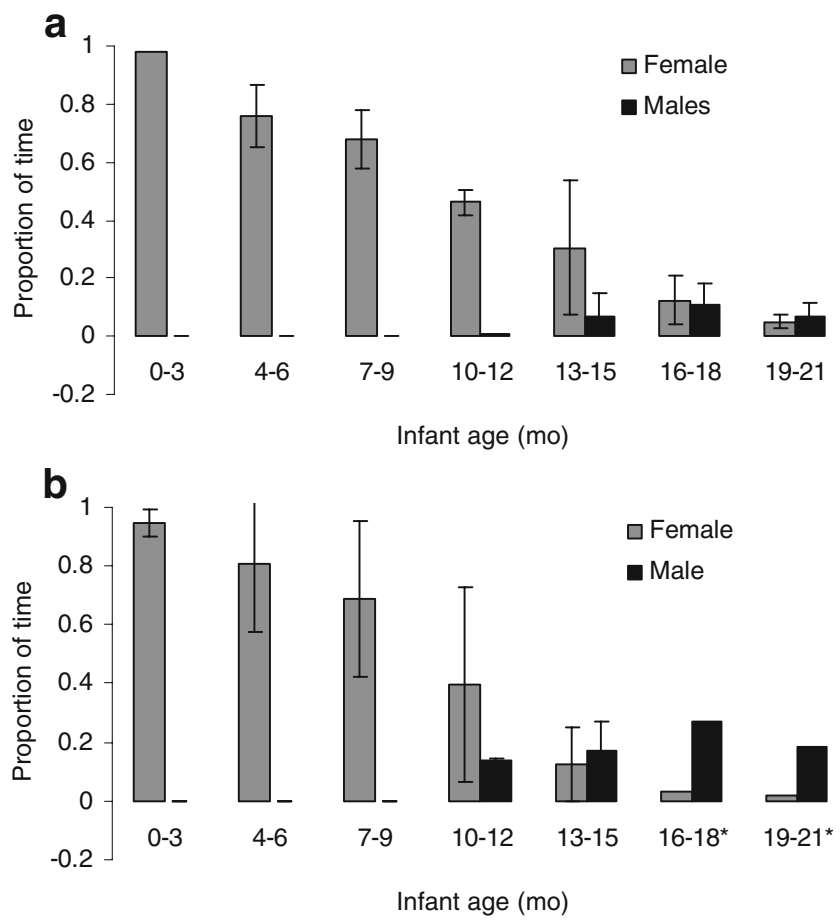

Fig. 2 a Proportion of time that females and males in polyandrous groups spent carrying infants. b Proportion of time that females and males in socially monogamous groups spent carrying infants. Bars represent the means of individual means for each 3-month period \pm SD. Data from only a single monogamous group were available for ages 16-21 months (asterisk). Therefore, no error bars are presented for these values

Both males and females spent a higher proportion of time carrying infants while traveling than while engaging in other activities (one-tailed Wilcoxon signed-rank test; individual means, paired by individual, females: $Z=-2.023, N=5, p=$ 0.031; males: $Z=-1.960, N=8, p=0.027$ ). While female time spent carrying infants declined steadily from birth to age 2 years, the proportion of time that mothers carried infants during travel remained very high throughout the first year of infant life. Independent travel by an infant younger than 9 months of age was never observed, and infants spent less than 0.05 of their time traveling independently between ages 10 and 12 months. Between ages 15 and 20 months, the rate of independent travel increased (Fig. 3) and by age 21 months, most infants spent as much time traveling independently as adults. Nonetheless, adults did occasionally carry infants over 21 months of age, suggesting that even older infants may rely on adults for transportation across large gaps, at high speeds, or when fatigued.

Female care decreased as male care increased

In groups $\mathrm{A}, \mathrm{C}, \mathrm{F}$, and $\mathrm{G}$, at least one male provided a substantial quantity of care for the infant (defined as spending a mean proportion of $\geq 0.05$ of time carrying the infant during at least one 3-month block), and the onset of male care was associated with a drop of at least 0.30 in the mean proportion of time that the female spent carrying the infant between two consecutive 3-month periods. Conversely, in group B where neither male provided a substantial quantity of infant care, the largest drop in the mean proportion of female time spent carrying the infant between consecutive 3 -month periods was 0.15 .

To quantitatively assess the relationship between male care (i.e., the quantity of care provided by all males in a group) and female care, I grouped months into categories based on the mean proportion of time that infants were cared for by males: $<0.05=$ little care, $0.05-0.149=$ moderate care, and $\geq 0.15=$ maximum care. I then examined the relationship between male care class and female care (the mean proportion of time that each female spent caring for an infant in a given month) using a general linear mixed model ANOVA with male care category as a factor and infant age (between 9 and 21 months) as a repeated measure for each subject. There was a significant effect of male care class on the quantity of care provided by females $\left(F_{2,31.9}=8.917, p=0.001\right)$. When infants received more care from males, they received less care from their mothers.

Infants in monogamous groups received more care than infants in polyandrous groups

I compared the quantity of care provided by males in groups classified as socially monogamous (groups F and $\mathrm{G}$ ) and groups classified as polyandrous (groups A, B, and C) to examine the relationship between grouping pattern and male care. Males living in polyandrous groups spent significantly lower proportions of time caring for infants than did males living in socially monogamous groups (onetailed Mann-Whitney $U$ test using individual means for

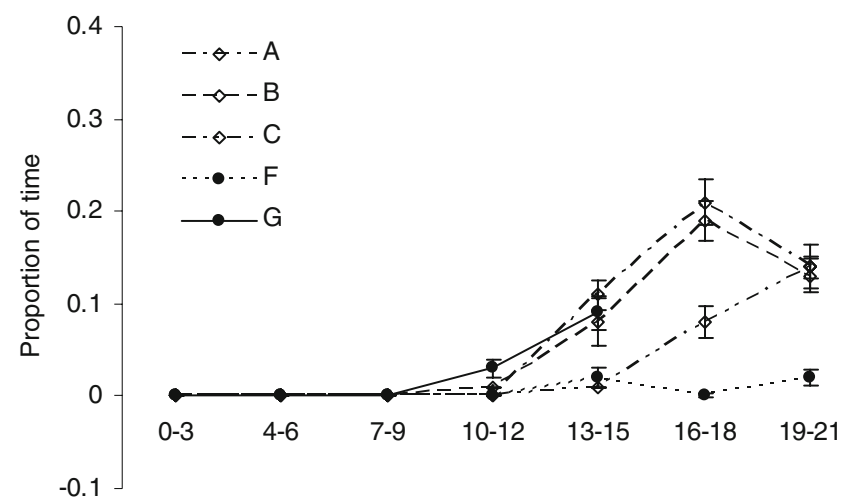

Infant age (mo)

Fig. 3 The mean proportion of time that each infant spent traveling independently. Values represent the individual means for each 3month period \pm SE. Infants from polyandrous groups are indicated with open diamonds. Infants from socially monogamous groups are indicated with closed circles 
each male, $\left.U^{\prime}=12, N_{1}=6, N_{2}=2, p=0.046\right)$. However, as two males were present in each polyandrous group, it is also important to consider the total contribution of males to infant care in groups containing one and two sexually active males. Infants in monogamous groups received more care from males than infants in polyandrous groups, even when the contributions from both males were considered. Infants were carried by monogamous males $0.134 \pm 0.029$ (mean \pm SE) of the time at age $10-12$ months, and $0.274 \pm$ 0.022 of the time at age 16-18 months, whereas infants were carried by polyandrous males only $0.007 \pm 0.002$ of the time at age $10-12$ months, and $0.119 \pm 0.032$ of the time at age 16-18 months (Fig. 2).

Male caring behavior was not associated with male-female social relationships

Male care has been described as a courtship behavior in some primate species (Smuts and Gubernick 1992), suggesting that there may be a relationship between male caring behavior and the strength of male-female social relationships. I was not able to directly test the hypothesis that caring males had a higher probability of paternity of the female's subsequent offspring than less caring males. However, I did examine the relationship between male care and variables reflecting the strength of male-female social bonds. There was no significant correlation between the mean proportion of time that males spent caring for infants and (a) the mean proportion of time that the same males spent within $20 \mathrm{~m}$ of the infant's mothers, (b) the mean interindividual distance between the male and the infant's mother, or (c) the mean proportion of time that the male spent in social grooming interactions with the infants' mother for infants of any age (Table 1). These results suggest that males providing more care for infants do not exhibit closer spatial cohesion or more frequent affiliative interaction with females than males providing less care.

Table 1 Results of the analyses of the relationship between the mean proportions of time that males spent caring for an infant of a given age and behavioral indicators of male-female social bond strength (individual means of daily means)

\begin{tabular}{lllll}
\hline Variable & $\begin{array}{l}\text { Infant age } \\
\text { (months) }\end{array}$ & $r$ & $N$ & $p$ \\
\hline Time spent $\leq 20 \mathrm{~m}$ from & $10-12$ & -0.306 & 8 & 0.438 \\
female & $13-15$ & -0.338 & 8 & 0.412 \\
& $16-18$ & -0.055 & 6 & 0.918 \\
Mean interindividual & $10-12$ & 0.116 & 8 & 0.784 \\
distance with female & $13-15$ & -0.165 & 8 & 0.696 \\
& $16-18$ & -0.137 & 6 & 0.769 \\
Time spent social & $10-12$ & 0.169 & 8 & 0.689 \\
grooming with female & $13-15$ & 0.077 & 8 & 0.857 \\
& $16-18$ & -0.208 & 6 & 0.693 \\
\hline
\end{tabular}

Copulation rates (mean copulations per day) for each male/ female dyad did not significantly differ in the 3-month periods before, including, and following the onset of substantial male care (ANOVA; AMI: $F_{2,26}=0.471, p=0.630$; AMU: $F_{2,23}=1.240, p=0.310$; CGO: $F_{2,32}=0.642, p=0.533$; CKR: $F_{2,30}=0.648, p=0.531$; FRE: $F_{2,27}=2.162, p=0.136$; GAT: $\left.F_{2,23}=3.150, p=0.064\right)$, suggesting that the onset of male care was not associated with an immediate change in patterns of sexual interactions of male-female dyads.

Male care did not increase total care received by infants

To assess the impacts of male care on infants, I used general linear mixed model ANOVA to examine the relationship between male care class (defined as above) and the total quantity of care that infants received (dependent variable) with infant age as a repeated measure. There was no significant effect of male care class on the total care received by infants $\left(F_{2,32.8}=2.482, p=0.099\right)$. This suggests that differences in male contributions to infant care do not result in detectable differences in the net amount of care received by the infants, but rather that females compensate for the variation in male care by adjusting their own contribution to infant care.

\section{Mothers providing more care had longer IBI}

The IBI between the study infant and the subsequent infant of all study females are known to within a few weeks (Table 2). I examined the relationship between the total quantity of care received by infants and IBI. The total proportion of time that infants of ages $0-14$ months spent receiving care from adults was a significant predictor of IBI $(r=0.938, N=5, F=21.873, p=0.018)$.

Table 2 Estimated birth dates of study infants and of their younger siblings with IBI

\begin{tabular}{llll}
\hline Female & $\begin{array}{l}\text { Study infant } \\
\text { birth date }\end{array}$ & $\begin{array}{l}\text { Subsequent infant } \\
\text { birth date }\end{array}$ & $\begin{array}{l}\text { IBI } \\
\text { (months) }\end{array}$ \\
\hline AMA & July 13, 2000 & May 13, 2003 & 34.0 \\
BAM & July 18, 2000 & April 13, 2003 & 32.8 \\
CON & July 7, 2000 & June 13, 2003 & 35.2 \\
FRI & December 28, 2000 & March 2, 2004 & 38.1 \\
GAR & May 1, 2001 & September 15, 2003 & 28.5 \\
\hline
\end{tabular}

Siamang gestation periods are estimated to be 6.2-7.9 months (Geissmann 1991).

${ }^{\text {a }}$ Birth date known to within 2 weeks.

${ }^{\mathrm{b}}$ Birth occurred during an 8 -week period during which the group was not followed. The birth date is estimated to have occurred early in this period based on infant size, hair cover, and behavior when first observed.

${ }^{\mathrm{c}}$ Birth date known to within 1 day. 
If male care functions to reduce energetic stress on the female, then increased infant care by males should be associated with reduced IBI. However, quantification of the effects of male care is not straightforward, as male care of infants is not an instantaneous event; male care is a series of interactions over time, which varied between males in its intensity, timing, and duration.

As female siamangs adjust their caring behavior in the presence of a caring male, I first examined the relationship between female care and IBI directly. The mean proportion of time that females spent caring for infants (mean of daily means of hourly proportions of time) between the ages of 0 and 14 months was a significant predictor of IBI $(r=0.963$, $N=5, F=38.667, p=0.008$; Fig. 4). These data confirm that female investment in the current infant is positively related to the interval between the births of the current and subsequent infants.

The mean proportion of time that males in each group spent caring for infants (mean of daily means of hourly proportions of time) between the ages of 0 and 14 months was not a significant predictor of maternal IBI $(r=0.260$, $N=5, F=0.217, p=0.673)$. However, the contribution of males to infant care was smaller and more variable than the contribution of females, which would make effects more difficult to detect in a sample of this size. If male care is functionally associated with variation in female IBI, this relationship may be mediated by changes in female care patterns associated with the onset of male care. As the onset of male care was associated with a dramatic drop in female care in most groups, it is appropriate to examine the relationship between the infant age at which this drop occurred and IBI. However, as males in group B provided little care, I used the age at which female care dropped below a threshold value suggested by the patterns of care in the other four groups as a proxy for the timing of the drop in female care to allow comparisons across all study

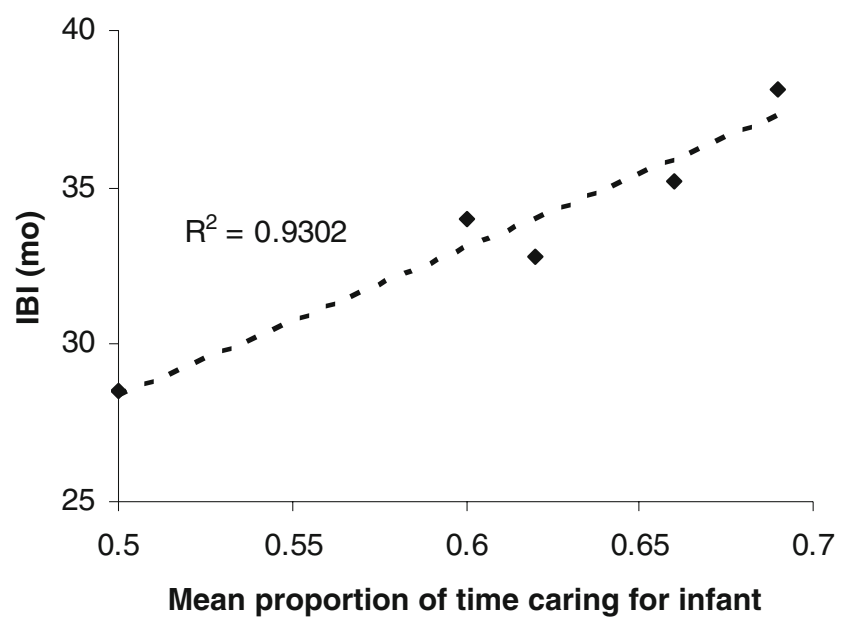

Fig. 4 The mean female time spent caring for infants from ages 0 to 15 months plotted against the IBI groups. Females in groups with caring males (groups A, C, F, and G) spent a mean proportion of 0.522 of time caring for infants in the 3-month interval before the drop in care associated with the onset of substantial male care. Therefore, I used regression analysis to examine the relationship between the infant age (in 3-month blocks) at which the quantity of female care dropped below 0.522 and the female's IBI. The infant age at which the proportion of time the female spent caring for her infant dropped below 0.522 was a strong predictor of female IBI $(r=0.941, N=5$, $F=23.065, p=0.017$ ). These results suggest that the timing of onset of male care may be functionally associated with the IBI.

\section{Discussion}

The relationship between mating systems and patterns of parental care

In several facultatively polyandrous mammalian (Bales et al. 2000; Creel and Creel 2002; Garber 1997; Goldizen 1987a, b; Keane et al. 1994; Schaffner and French 2004) and avian (Burke et al. 1989; Davies 1986; Faaborg et al. 1995; Hartley et al. 1995; Hatchwell and Davies 1990) species, polyandry is associated with helping behavior by secondary males, resulting in improved offspring survivorship, allowing reduced parental effort by females and primary males, or both. For example, wild saddle-back tamarins (Saguinus fuscicollis) have never been observed attempting reproduction in the absence of helpers (Goldizen 1987a), and facultative polyandry in several species of callitrichid primates is associated with extensive care by secondary males, coupled with reduced care by primary males and females (e.g., Achenbach and Snowdon 2002; Bales et al. 2000; Fite et al. 2005). Therefore, callitrichid females, infants, primary males, and secondary males may all benefit from cooperative polyandry. In dunnocks (Prunella modularis), however, care by secondary males improves offspring survivorship, benefiting females and offspring, but the reproductive success of polyandrous males is lower than that of males in pairs or polygynous groups, creating a potential conflict of interest between males and females (Davies 1986; Davies and Houston 1986).

In this study, all males in polyandrous groups did provide care for infants, but the quantity of care provided by all males in each polyandrous group combined was substantially lower than the quantity of care provided by males in socially monogamous groups. Therefore, in stark contrast to other facultatively polyandrous systems and to prediction 2, polyandrous siamang females not only did not receive more male help, but may actually be forced to 
accept lower levels of male help relative to females living in pairs, and may therefore pay an energetic cost for polyandry.

Similarly, infants in polyandrous groups did not receive more care than infants in monogamous groups (contrary to prediction 1a), and the results do not suggest a mechanism by which the presence of a second male should directly result in improved infant survivorship. Secondary males in polyandrous siamang groups may benefit from their association with a social group and from sexual access to the group female. However, this study could not identify potential benefits of polyandry for primary siamang males. Primary males did reduce their paternal effort in the presence of secondary males which may reduce their costs of reproduction relative to monogamous males. However, this reduction in paternal effort was not associated with substantial helping behavior by the secondary male (and therefore is not consistent with prediction $1 \mathrm{~b}$ ), but rather by an increase in maternal effort. If males benefit from their reduced parental effort in polyandrous groups, then why don't males in monogamous groups adopt the same strategy? It is possible that the mere presence of secondary males results in enhanced protection of infants from predators or hostile conspecifics, reduced infant need for direct forms of care, but if this is true, then it is unclear why mothers should compensate for reduced male care in polyandrous groups.

Several studies suggest that vertebrate males may adjust their caring behavior in response to the variation in their certainty of paternity (e.g., Buchan et al. 2003; Burke et al. 1989; Chuang-Dobbs et al. 2001; Dixon et al. 1994; Lifjeld et al. 1998; Neff and Gross 2001; Sheldon 2002). Accordingly, the reduced male care in polyandrous groups observed in this study may be a response to reduced certainty of paternity. However, as siamang group compositions often remain stable across several breeding attempts (Fig. 1), polyandry may be associated with both reduced certainty of paternity of the current infant and reduced probability of paternity of the female's future infants. Both could contribute to reduced paternal care in polyandrous groups.

Siamangs are sexually monomorphic in canine and body size. Therefore, polyandrous grouping in the apparent absence of benefits for females and primary males is puzzling, as a female should be able to cooperate with one male to evict the other should it be in her interest to do so. Forced copulation has not been reported in any gibbon species, and in this study, female rejection of copulation attempts never resulted in harassment by males. Therefore, the females' willingness to copulate with both males in polyandrous groups is difficult to explain if retention of second males is costly to females. Similarly, rates of aggression among males in polyandrous groups were very low, and both males were spatially and socially cohesive with other group members of both sexes (Lappan 2007b), suggesting tolerance of polyandry by primary males. These observations suggest that while females and primary males may experience costs of polyandry in terms of reduced help with infant care (females), and reduced certainty of paternity (primary males), they may also gain some benefit not identified in this study.

A relationship between density or habitat quality and mating system has been documented for several bird species (Davies and Lundberg 1984; Emlen 1982; Rossmanith et al. 2006). In Tasmanian native hens (Gallinula mortierii) and pukekos (Porphyrio porphyrio), polyandry is not associated with reproductive advantages, but polyandrous males share higher-quality territories than monogamous males (Craig 1984; Goldizen et al. 1998). Similarly, preliminary data suggest that larger siamang groups are more likely to "win" in intergroup encounters at Way Canguk (Kinnaird and O'Brien, unpublished data), suggesting that polyandrous groups may have a territorial advantage over monogamous groups. However, the relationship between territory quality and grouping patterns in siamangs has yet to be examined in detail.

The effects of male care for infants, females, and males

The onset of male care in siamangs occurred during a period in which infants still displayed substantial locomotor dependence on adults (Figs. 2 and 3), suggesting that male parental care has the potential to affect infant survivorship or development. However, this study did not detect an effect of male care on the total quantity of care that infants received, and all study infants survived despite substantial variation in male care. Male care in this population appears to replace female care, rather than supplementing it, resulting in no discernible benefit for the infant in terms of increased care.

As infant care in mammals involves both lactation and nonlactational care, infants may also benefit if replacement of female care with male care permits greater female investment in lactation, as has been suggested for callitrichid primates (Achenbach and Snowdon 2002; Garber and Leigh 1997; Goldizen 1987a; Snowdon 1996). In most callitrichids, the onset of male care occurs shortly after birth, before or during the period of peak lactation (Garber 1997). By freeing females from the energetic burden of infant carrying during this period, male care in callitrichids may allow females to invest heavily in milk production, facilitating rapid postnatal growth (Garber and Leigh 1997; Goldizen 1987a). However, the timing of male care in siamangs suggests that the effects of male care on female lactational effort are probably negligible, as males rarely provided care before infant age 10 months, and all study 
infants consumed solids by ages 3-7 months, and spent little time suckling after age 11 months (Lappan 2005).

Male care may have provided infants with benefits not quantified in this study. For example, the youngest juvenile in a group invariably shared a sleeping site with an adult male after the birth of a new infant while mothers and infants shared another site and all other individuals slept alone. Adult males were also potential play and social partners for juveniles. These observations suggest that young siamangs may benefit in the juvenile life stage from the relationships that they establish with males during infancy.

Comparative studies of anthropoid primates suggest that nonmaternal care primarily benefits mothers, rather than infants (Mitani and Watts 1997; Ross and MacLarnon 2000), and in marmosets and tamarins, females receiving more male help invested less in the current reproductive attempt than females receiving less help, which may have increased their chances of conception in the first postpartum ovulation (Fite et al. 2005; Sánchez et al. 1999). The clear positive relationship between female care and IBI in siamangs (Fig. 4) and the relationship between the drop in female care associated with the onset of male care and IBI suggest that male care may be functionally important in reducing the duration of female residual infertility after the cessation of lactation.

Comparative studies suggest that IBIs increase with body mass within phylogenetic groupings (Purvis et al. 2003). Information about IBI is unavailable for most gibbon taxa, but the mean siamang IBI (2.8 years) is similar to those of Hylobates lar (3.4 years; Reichard 2003), H. agilis (3.2 years; Mitani 1990a), and H. klossii (3.3 years; Tilson 1981), while the mean siamang mass is $>80 \%$ higher (Jungers and Smith 1997). This suggests a possible relationship between male care and reduced female investment in each infant among gibbons. However, given the limited data available from gibbons and the number of potential confounding variables, it is difficult to draw firm conclusions about the relationship between nonmaternal care and IBI in this family.

Male care of infants may function as a courtship behavior (Smuts and Gubernick 1992), and the onset of male care in tamarins occurs shortly after birth and is temporally associated with postpartum ovulation (French 1983; Garber 1997; Sánchez et al. 1999), which suggests immediate benefits to primary males in the form of increased access to fertile females. However, this study did not detect a relationship between siamang male caring behavior and patterns of spatial cohesion or affiliative interaction with females, and the onset of male care was not temporally associated with the resumption of copulation (which occurred several months before the onset of male care) or changes in female copulation rates.

Sexual conflict over the quantity of care provided by adults of each sex can reduce male fitness if females reduce their contribution in the presence of a caring male (Royle et al. 2002). However, in the Way Canguk study population, siamang group compositions were generally fairly stable across multiple reproductive attempts (Fig. 1), and in this and other studies at the site (e.g. Kinnaird and O'Brien, unpublished data; Nurcahyo, unpublished data) copulations between members of different social groups have not been observed. While even low rates of extragroup copulation may result in substantial rates of extragroup paternity, these data nonetheless suggest that the largest component of male direct fitness is likely to be derived from reproduction within the social group. Therefore, male strategies involving investment in the fertility of the group female may be favored over strategies associated with lower female reproductive rates.

The behavior of the infants themselves may also affect infant care patterns. Indeed, anecdotal evidence suggests that infants are far from merely being passive recipients of parental care. Siamang mothers in this study were not restrictive of the movements of infants above about 6 months of age, and all five study infants persistently solicited care from males, particularly during travel. Such observations make it clear that the infants themselves likely play an active role in determining patterns of parental care, and that another side of this story remains to be told.

Acknowledgments Funding for this research was provided by the Leakey Foundation, Sigma Xi, the Fulbright Student Program, New York University, the New York Consortium for Evolutionary Primatology, and the Margaret and Herman Sokol Foundation, and during the writing stages, by Ewha Womans University and the Amore Pacific Foundation. Permission to conduct research in Indonesia was granted by the Indonesian Institute of Sciences (LIPI), and permission to conduct research in the Bukit Barisan Selatan National Park was granted by the Indonesian Ministry of Forestry's Department for the Protection and Conservation of Nature (PHKA). I thank the American-Indonesian Exchange Foundation (AMINEF), Universitas Indonesia and the Wildlife Conservation Society-Indonesia Program for considerable logistical assistance in Indonesia, and Anton Nurcayho, Maya Dewi Prasetyaningrum, Mohammad Iqbal, Teguh Priyanto, Tedy Presetya Utama, Janjiyanto, Sutarmin, Martin Trisunu Wibowo, and Abdul Roshyd for their assistance in the field. Thanks to Marina Cords, Roberto Delgado, Tony Di Fiore, Terry Harrison, and Clifford Jolly for the helpful comments on the dissertation chapter on which this manuscript is based, and to Susan Alberts and three anonymous reviewers for many helpful comments on earlier versions of this manuscript. Thanks to Tim O'Brien and Margaret Kinnaird for many helpful discussions and for sharing unpublished data. The research described in this manuscript was conducted with permission from the government of Indonesia, and was conducted in full compliance with the laws of the Republic of Indonesia.

\section{References}

Achenbach GG, Snowdon CT (2002) Costs of caregiving: weight loss in captive adult male cotton-top tamarins (Saguinus oedipus) following the birth of infants. Int J Primatol 23:179-189 
Ahsan MF (2000) Socio-ecology of the hoolock gibbon (Hylobates hoolock) in two forests of Bangladesh. In: The apes: challenges for the 21st century. Brookfield Zoo, 10-13 May,Chicago Zoological Park, Chicago, pp 286-299

Alberts S (1987) Parental care in captive siamangs (Hylobates syndactylus). Zoo Biol 6:401-406

Bales K, Dietz J, Baker A, Miller K, Tardif S (2000) Effects of allocare-givers on fitness of infants and parents in callitrichid primates. Folia Primatol 71:27-38

Bales K, French JA, Dietz J (2002) Explaining variation in maternal care in a cooperatively breeding mammal. Anim Behav 63:453-461

Bester-Meredith JK, Marler CA (2003) The association between male offspring aggression and paternal and maternal behavior of Peromyscus mice. Ethology 109:797-808

Borries C, Launhardt K, Epplen C, Epplen JT, Winkler P (1999) Males as infant protectors in Hanuman langurs (Presbytis entellus) living in multimale groups - defence pattern, paternity, and sexual behaviour. Behav Ecol 46:350-356

Buchan JC, Alberts SC, Silk JB, Altmann J (2003) True paternal care in a multi-male primate society. Nature 425:179-181

Burke T, Davies NB, Bruford MW, Hatchwell BJ (1989) Paternal care and mating behaviour of polyandrous dunnocks Prunella modularis related to paternity by DNA fingerprinting. Nature 338:249-251

Cantoni D, Brown RE (1997) Paternal investment and reproductive success in the California mouse, Peromyscus californicus. Anim Behav 54:377-386

Carpenter C (1940) A field study in Siam of the behavior and social relations of the gibbon (Hylobates lar). Comparative Psychology Monographs 16:1-201

Chivers DJ (1974) The Siamang in Malaya: a field study of a primate in tropical rain forest, vol 4, 1st edn. Karger, Basel

Chivers DJ, Raemaekers JJ (1980) Long-term changes in behavior. In: Chivers DJ (ed) Malayan forest primates: ten years study in tropical rain forest. Plenum, New York, pp 209-258

Chuang-Dobbs HC, S WM, T HR (2001) Paternity and parental care in the black-throated blue warbler, Dendroica caerulescens. Anim Behav 62:83-92

Cleveland J, Snowdon CT (1984) Social development during the first twenty weeks in the cotton-top tamarin (Saguinus oedipus). Anim Behav 32:432-444

Clutton-Brock TH (1991) The evolution of parental care. Princeton University Press, Princeton

Craig JL (1984) Are communal pukeko caught in the prisoner's dilemma? Behav Ecol Sociobiol 14:147-150

Creel SR, Creel NM (2002) The African wild dog: behaviour, ecology and conservation. Princeton University Press, Princeton

Davies NB (1986) Reproductive success of dunnocks, Prunella modularis, in a variable mating system. I. Factors influencing provisioning rate, nestling weight and fledging success. J Anim Ecol 55:123-138

Davies NB, Hatchwell BJ (1992) The value of male parental care and its influence on reproductive allocation by male and female dunnocks. J Anim Ecol 61:259-272

Davies NB, Houston AI (1986) Reproductive success of dunnocks, Prunella modularis, in a variable mating system. II. Conflicts of interest among breeding adults. J Anim Ecol 55:139-154

Davies NB, Lundberg A (1984) Food distribution and a variable mating system in the dunnock, Prunella modularis. J Anim Ecol 53:895-912

Dielentheis TF, Zaiss E, Geissmann T (1991) Infant care in a family of siamangs (Hylobates syndactylus) with twin offspring at Berlin zoo. Zoo Biol 10:309-317

Dixon A, Ross D, O’Malley SLC, Burke T (1994) Paternal investment inversely related to degree of extra-pair paternity in the reed bunting. Nature 371:698-700
Dunbar RIM (1995) The mating system of callitrichid primates: I. conditions for the coevolution of pair bonding and twinning. Anim Behav 50:1057-1070

Emlen ST (1982) The evolution of helping. I. An ecological constraints model. Am Nat 119:29-39

Faaborg J, Parker PG, DeLay L, de Vries T, Bednarz JC, Paz SM, Naranjo J, Waite TA (1995) Confirmation of cooperative polyandry in the Galapagos hawk (Buteo galapagoensis). Behav Ecol Sociobiol 36:83-90

Fite JE, Patera KJ, French JA, Rukstalis M, Hopkins EC, Ross CN (2005) Opportunistic mothers: female marmosets (Callithrix kuhlii) reduce their investment in offspring when they have to, and when they can. Hum Evol 49:122-142

Frazier CRM, Trainor BC, Cravens CJ, Whitney TK, Marler CA (2006) Paternal behavior influences development of aggression and vasopressin expression in male California mouse offspring. Horm Behav 50:699-707

French JA (1983) Lactation and fertility: an examination of nursing and interbirth intervals in cotton-top tamarins (Saguinus o. oedipus). Folia Primatol 40:276-282

Fuentes A (2000) Hylobatid communities: changing views on pair bonding and social organization in hominoids. Am J Phys Anthropol 113:33-60

Garber PA (1997) One for all and breeding for one: cooperation and competition as a tamarin reproductive strategy. Evol Anthropol 6:187-199

Garber PA, Leigh SR (1997) Ontogenetic variation in small-bodied New World primates: implications for patterns of reproduction and infant care. Folia Primatol 68:1-22

Garber PA, Moya L, Malaga C (1984) A preliminary field study of the moustached tamarin monkey (Saguinus mystax) in northeastern Peru: questions concerned with the evolution of a communal breeding system. Folia Primatol 42:17-32

Geissmann T (1991) A reassessment of age of sexual maturity in Gibbons (Hylobates spp.). Am J Primatol 23:11-22

Gittins SP, Raemaekers JJ (1980) Siamang, lar and agile gibbons. In: Chivers DJ (ed) Malayan forest primates: ten years' study in tropical rain forest. Plenum, New York, pp 63-105

Goldizen AW (1987a) Facultative polyandry and the role of infantcarrying in wild saddle-back tamarins (Saguinus fuscicollis). Behav Ecol Sociobiol 20:99-109

Goldizen AW (1987b) Tamarins and marmosets: communal care of offspring. In: Smuts BB, Cheney DL, Seyfarth RM, Wrangham RW, Struhsaker TT (eds) Primate societies. University of Chicago Press, Chicago, pp 34-43

Goldizen AW, Putland DA, Goldizen AR (1998) Variable mating patterns in Tasmanian native hens (Gallinula mortierii): correlates of reproductive success. J Anim Ecol 67:307-317

Gubernick DJ, Teferi T (2000) Adaptive significance of male parental care in a monogamous mammal. Proc R Soc Lond B Biol Sci 267:147-150

Hartley IR, Davies NB, Hatchwell BJ, Desrochers A, Nebel D, Burke $\mathrm{T}$ (1995) The polygynandrous mating system of the alpine accentor, Prunella collaris. II. Multiple paternity and parental effort. Anim Behav 49:789-803

Hatchwell BJ, Davies NB (1990) Provisioning of nestlings by dunnocks, Prunella modularis, in pairs and trios compensation reactions by males and females. Behav Ecol Sociobiol 27:199209

Jennions MD, MacDonald DW (1994) Cooperative breeding in mammals. Trends Ecol Evol 9:89-93

Jungers WL, Smith RJ (1997) Body mass in comparative primatology. J Hum Evol 32:523-559

Keane B, Waser PM, Creel SR, Creel NM, Elliott LF, Minchella DJ (1994) Subordinate reproduction in dwarf mongooses. Anim Behav 47:65-75 
Kinnaird MF, O’Brien TG (1998) Ecological effects of wildfire on lowland rainforest in Sumatra. Conserv Biol 12:954-956

Kinnaird MF, O'Brien TG (2005) Fast foods of the forest: the influence of figs on primates and hornbills across Wallace's line. In: Dew JL, Boubli JP (eds) Tropical fruits and frugivores: the search for strong interactors. Springer, New York, pp 155184

Kleiman DG, Malcolm JR (1981) The evolution of male parental investment in mammals. In: Gubernick DJ, Klopfer PH (eds) Parental care in mammals. Plenum, New York, pp 347-387

Komers P, Brotherton P (1997) Female space use is the best predictor of monogamy in mammals. Proc $\mathrm{R}$ Soc Lond B Biol Sci 264:1261-1270

Lappan S (2005) Biparental care and male reproductive strategies in siamangs (Symphalangus syndactylus) in southern Sumatra. Unpublished Ph.D. thesis, New York University

Lappan S (2007a) Patterns of dispersal in Sumatran siamangs (Symphalangus syndactylus): preliminary mtDNA evidence suggests more frequent male than female dispersal to adjacent groups. Am J Primatol 69:692-698

Lappan S (2007b) Social relationships among males in multi-male siamang groups. Int J Primatol 28:369-387

Lifjeld JT, Slagsvold T, Ellegren H (1998) Experimentally reduced paternity affects paternal effort and reproductive success in pied flycatchers. Anim Behav 55:319-329

McInroy JKE, Brousmiche DG, Wynne-Edwards KE (2000) Fathers, fat, and maternal energetics in a biparental hamster: paternal presence determines the outcome of a current reproductive effort and adipose tissue limits subsequent reproductive effort. Horm Behav 37:399-409

Mitani JC (1990a) Demography of agile gibbons (Hylobates agilis). Int J Primatol 11:411-424

Mitani JC (1990b) Experimental field studies of Asian ape social systems. Int J Primatol 11:103-126

Mitani JC, Watts D (1997) The evolution of non-maternal caretaking among anthropoid primates: do helpers help? Behav Ecol Sociobiol 40:213-220

Neff BD, Gross MR (2001) Dynamic adjustment of parental care in response to perceived paternity. Proc R Soc Lond B Biol Sci 268:1559-1565

O'Brien TG, Kinnaird MF, Anton N, Prasetyaningrum MDP, Iqbal M (2003) Fire, demography and the persistence of siamang (Symphalangus syndactylus: Hylobatidae) in a Sumatran rainforest. Anim Conserv 6:115-121

Palombit RA (1992) Pair bonds and monogamy in wild siamang (Hylobates syndactylus) and white-handed gibbon (Hylobates lar) in northern Sumatra. Unpublished Ph.D. thesis, University of California, Davis

Palombit RA (1994) Dynamic pair bonds in hylobatids: implications regarding monogamous social systems. Behaviour 128:65-101

Palombit RA (1996) Pair bonds in monogamous apes: a comparison of the siamang (Hylobates syndactylus) and the white-handed gibbon (Hylobates lar). Behaviour 133:321-356

Price EC (1992) The benefits of helpers: effects of group and litter size on infant care in tamarins (Saguinus oedipus). Am J Primatol $26: 179-190$
Purvis A, Webster AJ, Agapow P, Jones KE, Isaac NJB (2003) Primate life histories and phylogeny. In: Kappeler PM, Pereira ME (eds) Primate life histories and socioecology. University of Chicago Press, Chicago, pp 25-40

Reichard U (2003) Social monogamy in gibbons: the male perspective. In: Reichard $\mathrm{U}$, Boesch $\mathrm{C}$ (eds) Monogamy: mating strategies and partnerships in birds, humans, and other mammals. Cambridge University Press, Cambridge, pp 190-213

Ross C, MacLarnon A (2000) The evolution of non-maternal care in anthropoid primates: a test of the hypotheses. Folia Primatol 71:93-113

Rossmanith E, Grimm V, Blaum N, Jeltsch F (2006) Behavioural flexibility in the mating system buffers population extinction: lessons from the lesser spotted woodpecker, Picoides minor. J Anim Ecol 75:540-548

Royle NJ, Hartley IR, Parker GA (2002) Sexual conflict reduces offspring fitness in zebra finches. Nature 416:733-736

Sánchez S, Peláez F, Gil-Bürmann C, Kaumanns W (1999) Costs of infant-carrying in the cotton-top tamarin (Saguinus oedipus). Am J Primatol 48:99-111

Schaffner CM, French JA (2004) Behavioral and endocrine responses in male marmosets to the establishment of multimale breeding groups: evidence for non-monopolizing facultative polyandry. Int J Primatol 25:709-732

Sheldon BC (2002) Relating paternity to paternal care. Philos Trans R Soc Lond B Biol Sci 357:341-350

Smuts BB, Gubernick DJ (1992) Male-infant relationships in nonhuman primates: paternal investment or mating effort? In: Hewlett BS (ed) Father-child relations: cultural and biosocial contexts. Aldine de Gruyter, New York, pp 1-30

Snowdon CT (1996) Infant care in cooperatively breeding species. In: Rosenblatt JS, Snowdon CT (eds) Parental care: evolution, mechanisms and adaptive significance. Academic, San Diego, pp 643-689

Sommer V, Reichard U (2000) Rethinking monogamy: the gibbon case. In: Kappeler PM (ed) Primate males. Cambridge University Press, Cambridge, pp 159-168

Tilson RL (1981) Family formation strategies of Kloss's gibbons. Folia Primatol 35:259-287

van Schaik CP, Dunbar RIM (1990) The evolution of monogamy in large primates: a new hypothesis and some crucial tests. Behaviour 115:30-61

van Schaik CP, Paul A (1997) Male care in primates: does it ever reflect paternity? Evol Anthropol 5:152-156

Webb JN, Houston AI, McNamara JM, Szekely T (1999) Multiple patterns of parental care. Anim Behav 58:983-993

Whitten PL (1987) Infants and adult males. In: Smuts BB, Cheney DL, Seyfarth RM, Wrangham RW, Struhsaker TT (eds) Primate societies, vol primate societies. University of Chicago Press, Chicago, pp 343-357

Wright PC (1990) Patterns of paternal care in primates. Int J Primatol 11:89-102

Wright HWY (2006) Paternal den attendance is the best predictor of offspring survival in the socially monogamous bat-eared fox. Anim Behav 71:503-510

Zar JH (1996) Biostatistical analysis, 3rd edn. Prentice Hall, Upper Saddle River, New Jersey 